\title{
A fractal-based model for soil water characteristic curve over entire range of water content
}

\author{
Tingxu Jin ${ }^{1}$, Xin $\mathrm{Cai}^{2}$, Yin Chen ${ }^{1}$, Shanshan Jiang ${ }^{1}$, Wei Wei ${ }^{1 \oplus *}$ \\ ${ }^{1}$ Institute of Geophysics and Geomatics, China University of Geosciences, Wuhan 430074, P. R. China \\ ${ }^{2}$ Zhongyuan University of Technology, Zhengzhou 450007, P. R. China
}

\section{Keywords:}

Fractal model

soil water characteristic curve

film flow

capillary flow

Cited as:

Jin, T., Cai, X., Chen, Y., Jiang, S.,

Wei, W. A fractal-based model for soil water characteristic curve over entire range of water content. Capillarity, 2019, 2(4): 66-75, doi:

10.26804/capi.2019.04.02.

\begin{abstract}
:
Soil water characteristic curve (SWCC) has been an important role in hydraulic engineering, civil engineer and petroleum engineering, etc. Most of SWCC models neglected the film flow in the dry state, so that they cannot accurately describe the SWCC over entire range of water content. In this work, an alternative fractal model is proposed to predict the SWCC over entire range of water content by combining Campbell and Shiozawa model and Tao model. The proposed model can well predict twelve sets of experimental data, and its parameters, including the fractal dimension, the saturated volumetric water content, the matric suction at oven-dry condition, and the air-entry value, accord with theoretical value. The results show that there is a strong linear relationship between volumetric water content and matrix suction in log-log scale for different fractal pore-size distribution of soils. In addition, good agreement is obtained between the experimental data and the model predictions in all of the cases.
\end{abstract}

\section{Introduction}

The soil water characteristic curve (SWCC) is usually used to describe the relationship between matric suction of soils and gravimetric/volumetric water content or the degree of saturation. It is one of the important hydraulic properties for modeling water transport process in porous media, there are various applications in the field of unsaturated soil mechanics (Wheeler, 1996; Gallipoli et al., 2003; Fredlund, 2006). The critical parameters, such as the shear strength, permeability of unsaturated porous media and stress-strain, are also related to SWCC (Fredlund et al., 1996; Assouline, 2001; Al Haj and Standing, 2016). However, the measurements of the SWCC is time-consuming because of highly complexity of structure and composition of soil. One of effective methods to solve the measurement problem is the development of theoretical model for predicting the SWCC of soils.

Over the past decades, various attempts have been made to present the SWCC equation of unsaturated soil. Brooks and Corey (1964) and Van Genuchten (1980) presented empirical equations to describe the experimental SWCCs, which are commonly exploited in various fields. Mbonimpa et al. (2006) presented a SWCC equation of deformable soil under increasing suction by means of volumetric shrinkage curve. Aubertin et al. (2003) developed a set of equations to estimate the SWCC from some basic geotechnical properties of soil. Yang and Lu (2012) derived a SWCC equation considering contact angle hysteresis by simplifying soil particles as the spherical particle model. On the basis of back propagation (BP) neural network algorithm and Arya-Paris model (Arya and Paris, 1981), Tao et al. (2017) developed a new calculation method for determining SWCC. However, these works neglect the flow process in dry condition, so it cannot accurately describe the relationship between matric suction and water volume of soils (Rossi and Nimmo, 1994; Silva and Grifoll, 2007).

In recent years, a great deal of studies has been carried out on the prediction of SWCC over the complete range of water content. For example, Lebeau and Konrad (2010) presented a SWCC model with considering the weighted average of the contributions of capillary flow and thin film flow. In SWCC model, the mechanics of thin film flow (Campbell and Shiozawa, 1992) and capillary flow (Kosugi, 1996) should be different. Zhang (2011) presented two models to describe SWCC over complete range of water content, where Brooks

${ }^{*}$ Corresponding author.

E-mail address: jintingxu@foxmail.com (T. Jin); 9937@zut.edu.cn (X. Cai); Agchen19930922@163.com (Y. Chen); gniger@126.com (S. Jiang); weiwei@cug.edu.cn (W. Wei). 2652-3310 (c) The Author(s) 2019.

Received October 25, 2019; revised November 5, 2019; accepted November 6, 2019; available online November 9, 2019. 
Table 1. Comparison of different SWCC models.

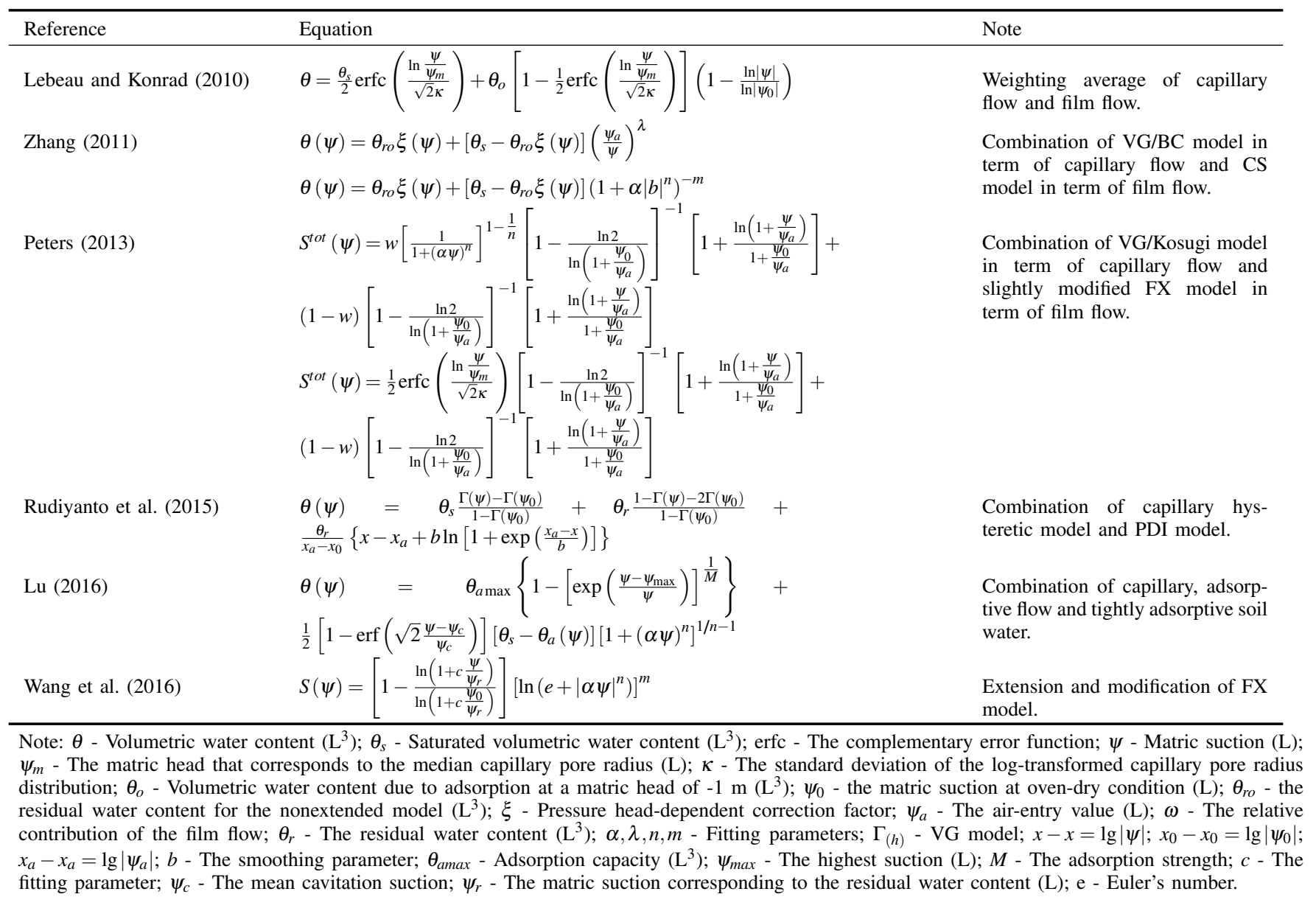

and Corey (BC) model (Brooks and Corey, 1964) and Van Genuchten (VG) model (Van Genuchten, 1980) were modified by adsorption-based Campbell and Shiozawa (CS) model (Campbell and Shiozawa, 1992). Peters (2013) introduced a new set of empirical hydraulic models to effectively describe water dynamics over complete range of water content. The new SWCC model was given by the weighted sum of a capillary and an adsorptive saturation term. The basic saturation functions for the capillary flow were the function of Van Genuchten (1980) model and Kosugi (1996) model. The basic saturation function for the film flow was given by a slight modification of the correction function of Fredlund et al. (1996). However, these two SWCC models have five fitting parameters. On the basis of capillary hysteresis phenomenon and Peter-DurnerIden (PDI) model (Iden and Durner, 2014), Rudiyanto et al. (2015) presented a SWCC model over complete range of water content by simultaneously considering capillary hysteretic, adsorptive water and capillary water. A smooth piecewise linear function was introduced in this SWCC model. Based on the assumption of local thermodynamic energy equilibrium, Lu (2016) generalized a SWCC equation including comprehension of soil-water interaction, which can account for capillary flow, adsorptive flow and tightly adsorptive water in different state of water content. This SWCC model over entire range of water content was defined with seven parameters. Wang et al. (2016) extended Fredlund and Xing (FX) model (Fredlund and Xing, 1994) to predict SWCC equation from the saturation to oven dryness. A slightly different correction function was employed in this SWCC model. Table 1 shows several common SWCC models over entire range of water content. Above works devote to improve the existing SWCC models, or combine capillary flow and film flow, to extend the traditional SWCC over entire range of water content.

Those existing models are so complex as to many empirical parameters. Pore structure information can be used to reduce the empirical parameters in SWCC model over entire range of water content (Perfect, 1999; De Bartolo et al., 2014). The fractal geometry is an effective tool to characterize micro-pore structure of soils (Mandelbrot, 1982; Kravchenko and Zhang, 1998). Moreover, the SWCC of soils over entire range of water content are closely related to its pore structure. However, few attempts have been used to establish SWCC model over entire range of water content based on the fractal geometry. In this paper, on the basis of the capillary flow model (Tao model) and film flow model (CS model), an alternative fractal model of SWCC over entire range of water content is presented. The comparison results between the proposed model and experimental data show the model can be effectively applied 
to predict the SWCC of soils.

\section{Model development}

\subsection{Fractal-based SWCC model}

\subsubsection{SWCC model in term of capillary flow}

The fractal geometry in soil science is an effective tool to characterize micro-pore structure of soils (Mandelbrot, 1982; Kravchenko and Zhang, 1998; Russell, 2014). For the poresize distribution (PSD) over a range of pore radius from minimum pore radius $r_{\min }$ to maximum pore radius $r_{\max }$, where $r_{\min }$ closely approaches to zero. As Mandelbrot (1982) presented, the cumulative volume $V(\leq r)$ of pores with radius less than or equal to pore radius $r$ is expressed as,

$$
V(\leq r)=C r^{3-D}
$$

where $C$ is a constant, $D$ is the fractal dimension and $r$ is pore radius of the connected pore space. Assuming that the pores with radius less than or equal to $r$ are completely filled with water, the volumetric water content $\theta$ can be denoted as follows (Tao et al., 2018),

$$
\theta=C r^{3-D}
$$

The soil sample is considered as completely saturated soil when the largest pores with $r_{\max }$ are filled with water. Therefore, the saturated volumetric water content $\theta_{s}$ can be generated by substituting $r$ with $r_{\max }$ in Eq. (2),

$$
\theta_{s}=C r_{\max }^{3-D}
$$

The relationship between matric suction and pore radius is derived by Young-Laplace equation,

$$
\psi=\frac{2 \sigma \cos \alpha}{r}
$$

where $\psi$ is the matric suction, $\sigma$ represents the surface tension and $\alpha$ denotes the contact angle. By substituting $r$ with $r_{\max }$ in the Eq. (4), the air-entry value $\psi_{a}$ corresponding to maximum pore radius $r_{\max }$ can be obtained as,

$$
\psi_{a}=\frac{2 \sigma \cos \alpha}{r_{\max }}
$$

Then, substituting Eq. (2) into Eq. (4), and Eq. (3) into Eq. (5), respectively, yields the following expressions,

$$
\begin{aligned}
& \theta=C\left(\frac{2 \sigma \cos \alpha}{\psi}\right)^{3-D} \\
& \theta_{s}=C\left(\frac{2 \sigma \cos \alpha}{\psi_{a}}\right)^{3-D}
\end{aligned}
$$

Dividing Eq. (6) by Eq. (7) gives,

$$
\theta=\theta_{s}\left(\frac{\psi_{a}}{\psi}\right)^{3-D}
$$

It is noted that Eq. (8) is only valid in the condition of water content controlled by capillary force. If the residual water content $\theta_{r}$ is simplified as zero, the SWCC equation developed by $\mathrm{Xu}$ (2004) is same as Eq. (8).

\subsubsection{SWCC model in term of film flow}

It has been recognized that adsorption force is the dominated force to hold water when soil is in dry condition, where a thin film of water can stretch over the surface of soil particle. Therefore, the relationship between matrix suction and thin film water content is influenced by van der Waals adsorptive forces, surface-water interactions, the thickness of thin film and electrostatic interaction (Tuller and Or, 2005; Tokunaga, 2009; Lebeau and Konrad, 2010), which results in the complexity and difficulty for the study on SWCC over complete range of water content. Campbell and Shiozawa (1992) established an empirical method to describe the SWCC in dry condition, which is expressed as,

$$
\lg \psi=a \theta+\lg \psi_{0}
$$

where $a$ is fitting parameter, $\psi_{0}$ corresponds to the matric suction at oven-dry condition (i.e., $\theta \approx 0$ ). Many attempts have been made to investigate the hydraulic properties of porous media using Eq. (9) (Zhang, 2011; Wang et al., 2016; Chen et al., 2017). These results showed that the model (Eq. (9)) for describing the hydraulic properties of porous media over the entire range of water content can predict water transport process well.

Taking the deformation of Eq. (9), there is,

$$
\theta=\frac{1}{a} \lg \psi-\frac{1}{a} \lg \psi_{0}
$$

Eq. (10) illustrates that the water content at low water content can decrease linearly with the matric suction in logarithmic plotting. It is usually used to describe the hydraulic properties at low water content.

\subsubsection{SWCC model over the complete range of water content}

Assuming that the contribution of film flow to SWCC is ignored at moderate water content, a fractal SWCC model accounting for capillary and thin film flow is written as,

Table 2. Soil properties of the testing data.

\begin{tabular}{llll}
\hline No. & Data set & $\theta_{s}$ & Reference \\
\hline 1 & Adelanto loam & 0.43 & Pachepsky et al. (1984) \\
2 & Pachapa loam & 0.46 & Pachepsky et al. (1984) \\
3 & Shonai sand & 0.43 & Mehta et al. (1994) \\
4 & Acheng silty clay loam & 0.44 & Lu et al. (2008) \\
5 & Beijing silt loam & 0.38 & Lu et al. (2008) \\
6 & Shijiazhuang silty clay loam & 0.4 & Lu et al. (2008) \\
7 & Wuqiao silt loam & 0.37 & Lu et al. (2008) \\
8 & Arizona silty soil-14 & 0.44 & Jensen et al. (2015) \\
9 & Danish sandy soil-L3 & 0.45 & Jensen et al. (2015) \\
10 & Seochang sandy clay & 0.42 & Oh et al. (2012) \\
11 & Georgia kaolinite & 0.57 & Likos and Lu (2003) \\
12 & Wyoming bentonite & 0.7 & Likos and Lu (2003) \\
\hline
\end{tabular}


Table 3. The fitted parameters for the new model.

\begin{tabular}{llllll}
\hline No. & Data set & $\boldsymbol{a}$ & $\psi_{a}(\mathbf{c m})$ & $\psi_{0}(\mathbf{c m})$ & $\boldsymbol{D}$ \\
\hline 1 & Adelanto loam & -19.45 & 106.08 & $6.63 \times 10^{6}$ & 2.775 \\
2 & Pachapa loam & -39.39 & 60.76 & $4.75 \times 10^{6}$ & 2.623 \\
3 & Shonai sand & -70.13 & 4.03 & $1.13 \times 10^{6}$ & 2.645 \\
4 & Acheng silty clay loam & -27.37 & 35.41 & $1.94 \times 10^{7}$ & 2.791 \\
5 & Beijing silt loam & -41.74 & 29.89 & $2.00 \times 10^{7}$ & 2.754 \\
6 & Shijiazhuang silty clay loam & -31.74 & 14.68 & $1.36 \times 10^{7}$ & 2.807 \\
7 & Wuqiao silt loam & -42.05 & 42.72 & $1.34 \times 10^{7}$ & 2.705 \\
8 & Arizona silty soil-14 & -20.43 & 8.19 & $5.02 \times 10^{6}$ & 2.844 \\
9 & Danish sandy soil-L3 & -33.47 & 20.15 & $7.23 \times 10^{6}$ & 2.807 \\
10 & Seochang sandy clay & -51.44 & 41.32 & $2.93 \times 10^{7}$ & 2.702 \\
11 & Georgia kaolinite & -13.74 & 150.72 & $1.54 \times 10^{6}$ & 2.783 \\
12 & Wyoming bentonite & -6.67 & 5542.68 & $2.64 \times 10^{6}$ & 2.481 \\
\hline
\end{tabular}

$$
\theta=\left\{\begin{array}{l}
\theta_{s}\left(\frac{\psi_{a}}{\psi}\right)^{3-D} \quad \psi_{a} \leq \psi \leq \psi_{r} \\
\frac{1}{a} \lg \psi-\frac{1}{a} \lg \psi_{0} \quad \psi_{r} \leq \psi
\end{array}\right.
$$

where $\psi_{r}$ is the matric suction corresponding to residual water content. $\psi_{r}$ is assumed to be the dividing point from capillary force regime to adsorptive force regime, and is commonly set to be $1,500 \mathrm{kPa}$, which can be converted to pressure head of 15,000 cm (Fredlund et al., 1996; Xu, 2004; Lu, 2016).

\subsection{Determination of model parameters}

In Eq. (11), the description of SWCC over entire range of water content is primarily dominated by five parameters: (1) the saturated volumetric water content $\theta_{s}$, (2) the air-entry value $\psi_{a}$, (3) the matric suction $\psi_{0}$ at oven-dry condition, (4) fractal dimension $D$ and (5) the fitting parameter $a$. $\theta_{s}$ is conveniently obtained by basic physic experiment of soil. Air-entry value $\psi_{a}$ can be determined by using Eq. (8) to fit experimental data. Likewise, the fitting parameter $a$ can be obtained by applying Eq. (10) to fit experimental data.

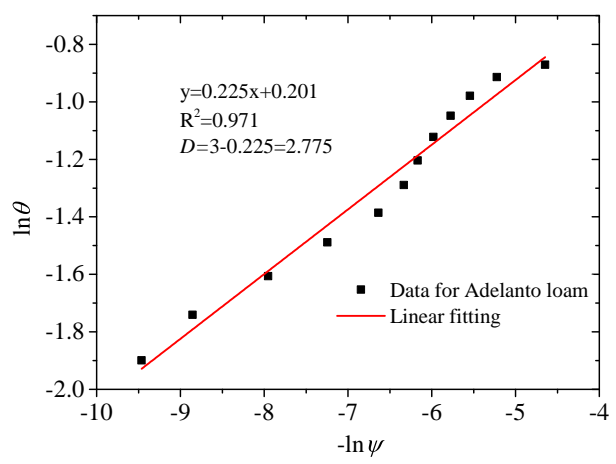

(a)
Conventionally, the matric suction $\psi_{0}$ at oven-dry condition is regarded to be $6.3 \times 10^{6} \mathrm{~cm}$ (Schneider and Goss, 2012; Wang et al., 2018). However, $\psi_{0}$ is captured by Eq. (10). In addition, fractal dimension $D$ can be obtained by taking the logarithm of both side of Eq. (8),

$$
\begin{aligned}
\ln \theta & =\ln \theta_{s}\left(\frac{\psi_{a}}{\psi}\right)^{3-D} \\
& =(3-D)(-\ln \psi)+(3-D) \ln \psi_{a}+\ln \theta_{s}
\end{aligned}
$$

Obviously, there is a linear relationship between $\ln \theta$ and $(-\ln \psi)$. Thus, fractal dimension $D$ can be determined by the slope $k$ in the plotting of $\ln \theta$ versus $(-\ln \psi)$.

\section{Result and discussion}

\subsection{Data for model testing}

Twelve sets of published SWCC data is applied to evaluate the performance of the proposed model (Eq. (11)). The data source and their saturated volumetric water content $\theta_{s}$ are shown in Table 2. For 12 soils data, volumetric water content

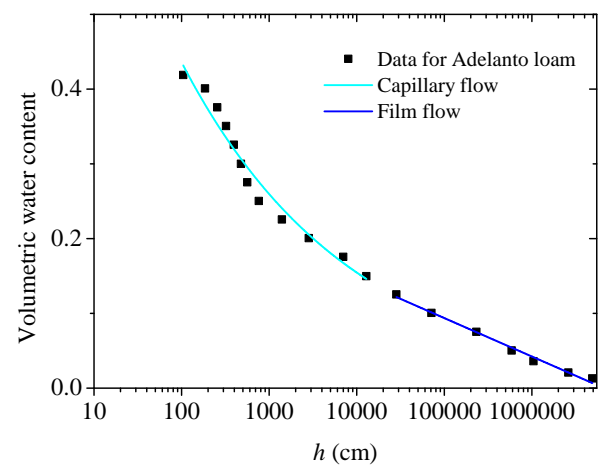

(b)

Fig. 1. (a) Determination of the values of fractal dimension through plotting experimental data of $\ln \theta$ against (-ln $\psi$ ) for Adelanto loam. (b) The model fitting results for Adelanto loam. 


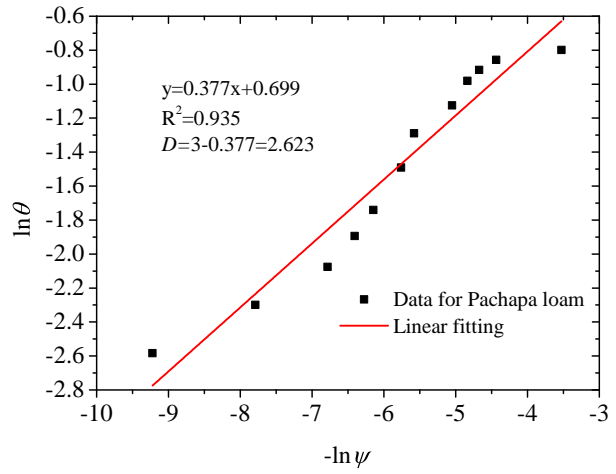

(a)

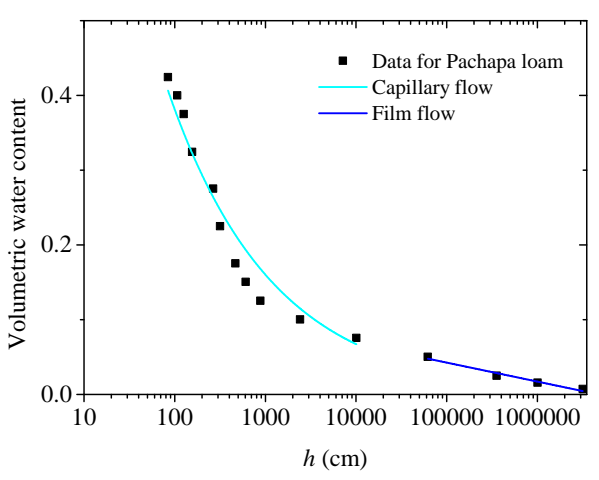

(b)

Fig. 2. (a) Determination of the values of fractal dimension through plotting experimental data of $\ln \theta$ against (-ln $\psi$ ) for Pachapa loam. (b) The model fitting results for Pachapa loam.

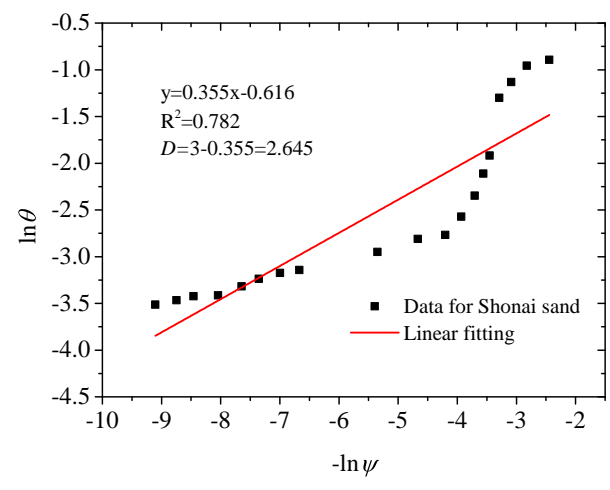

(a)

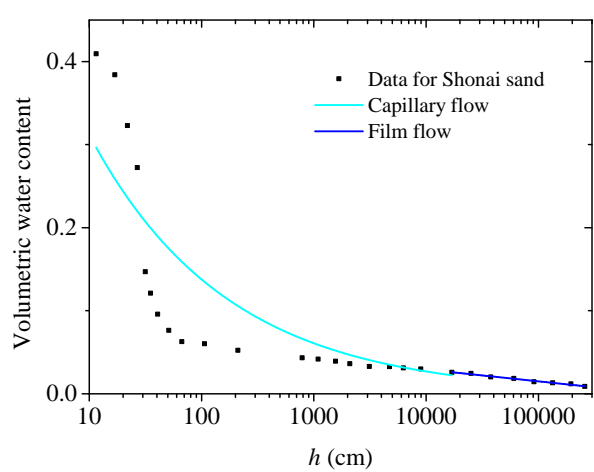

(b)

Fig. 3. (a) Determination of the values of fractal dimension through plotting experimental data $\operatorname{of} \ln \theta$ against (-ln $\psi$ ) for Shonai sand. (b) The model fitting results for Shonai sand.

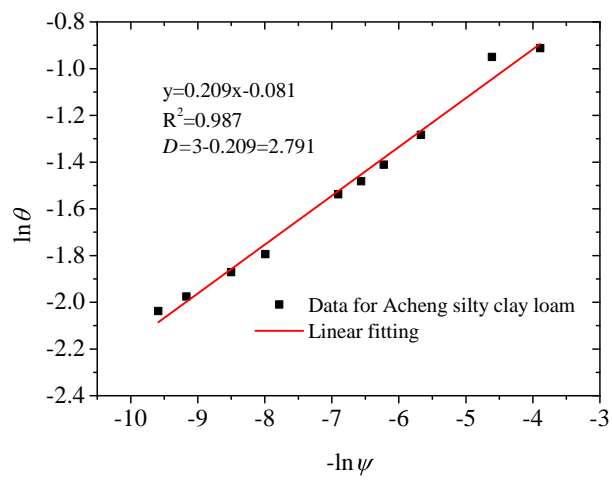

(a)

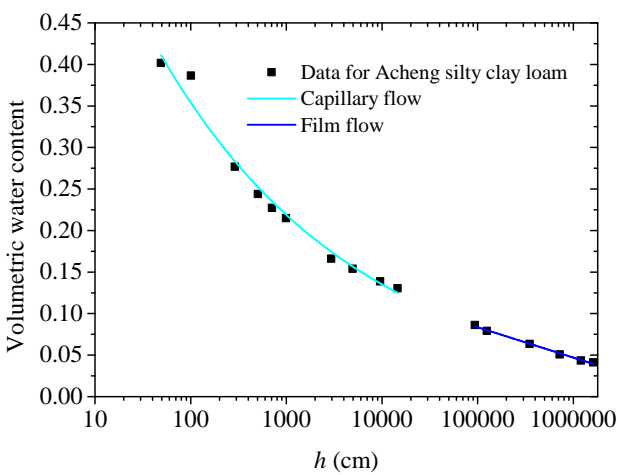

(b)

Fig. 4. (a) Determination of the values of fractal dimension through plotting experimental data of $\ln \theta$ against (-ln $\psi$ ) for Acheng silty clay loam. (b) The model fitting results for Acheng silty clay loam.

at saturated condition has been measured, the parameter $\theta_{s}$ can be set as the known values. Their references and properties of soils sample are listed in Table 2.

\subsection{Determination of model parameters}

By fitting the proposed model (Eq. (10)) wito the experimental data, $\psi_{a}, \psi_{0}$ and $a$ were determined as shown in Table 3. Meanwhile, fractal dimension $D$ was obtained by using Eq. (12). The fitting results of $D$ are given in Table 3, and the fitting process is that $(3-D)$ can be evaluated from the slope $k$ in the plotting of $\ln \theta$ versus $(-\ln \psi)$, then the fractal dimension can be determined as $D=3-k$, as shown in Fig. 1(a) - Fig. 12(a). We can observe that there is a strong linear relationship between $\ln \theta$ and $(-\ln \psi)$ for different fractal poresize distribution of soils in Fig. 1(a) - Fig. 12(a).

\subsection{Model testing results}

When fractal dimensions of twelve soils were calculated, only the experimental data ranging from $\psi_{a}$ to $\psi_{r}$ were adopted in Fig. 1(a) - Fig. 12(a). Because the SWCC in those 


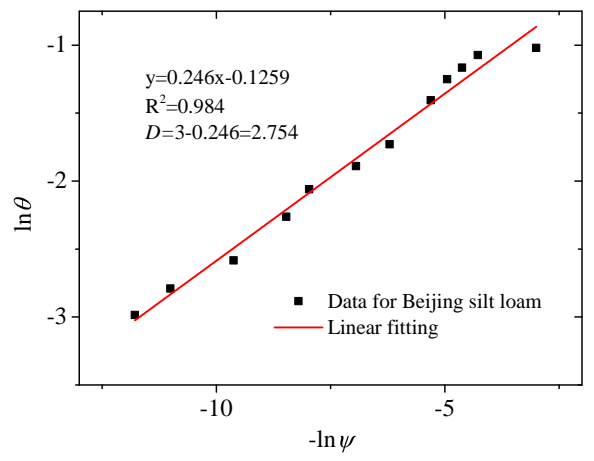

(a)

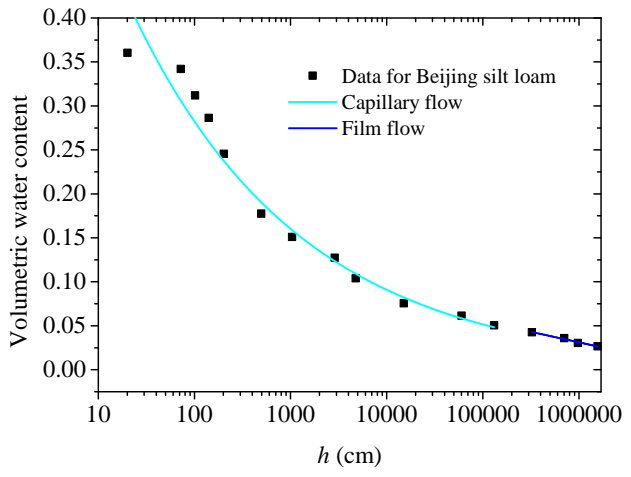

(b)

Fig. 5. (a) Determination of the values of fractal dimension through plotting experimental data of $\ln \theta$ against (-ln $\psi$ ) for Beijing silt loam. (b) The model fitting results for Beijing silt loam.

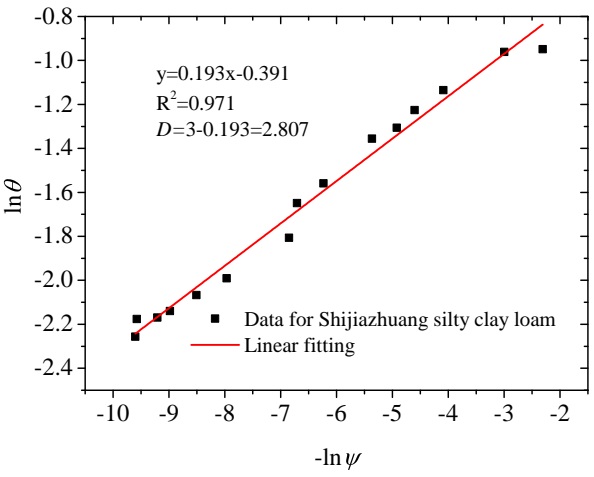

(a)

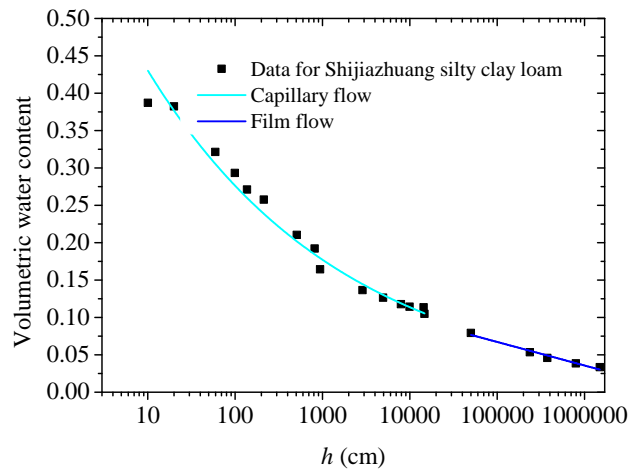

(b)

Fig. 6. (a) Determination of the values of fractal dimension through plotting experimental data of $\ln \theta$ against (-ln $\psi$ ) for Shijiazhuang silty clay loam. (b) The model fitting results for Shijiazhuang silty clay loam.

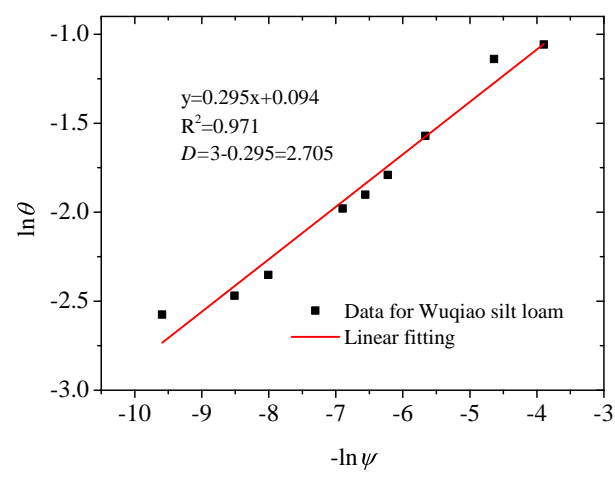

(a)

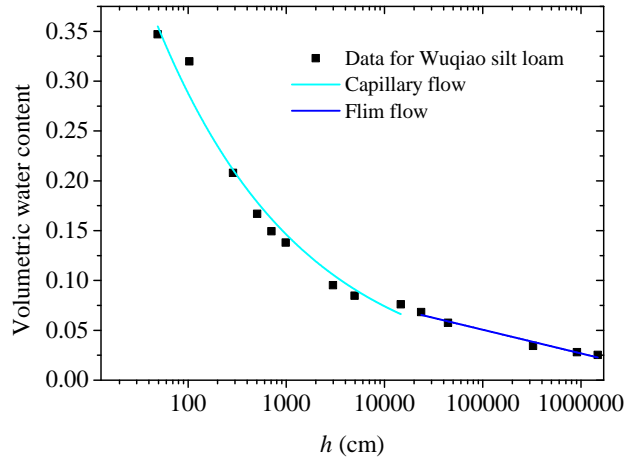

(b)

Fig. 7. (a) Determination of the values of fractal dimension through plotting experimental data of $\ln \theta$ against (-ln $\psi$ ) for Wuqiao silt loam. (b) The model fitting results for Wuqiao silt loam.

range of matrix suction is mainly controlled by the capillary force. The capillary force is related to micro-pore structure of soils which follows the theory of PSD of fractal geometry. The results show that the fitting correlation coefficient is 0.782 $\sim 0.987$ for all the experimental data, and the values of the fractal dimension are all in the range of $2-3$, which accords with theoretical value. As can be seen from Fig. 1(a) - Fig. $12(a)$, there is a strong linear correlation between $\ln \theta$ versus $(-\ln \psi)$ except Fig. 3(a), indicating that the fitting results of fractal dimension are reasonable. In Fig. 3(a), (-ln $\psi)$ shows a slightly linear relationship with $\ln \theta$.
As for air-enter value $\psi_{a}$, it can be seen from Table 3, the values of $\psi_{a}$ vary significantly for various soil samples, which vary in several orders of magnitude. There are three factors, such as soil texture, soil structure and soil temperature, cause the difference of orders of magnitude: (1) at the same matrix suction, the higher the clay content contributes to the enhancement of the soil water content, at the same water content, the higher the clay content results in the larger airenter value; (2) air-enter values of soils increase with the number of large pores; (3) conventionally, the viscosity of soil decreases as temperature increases. 


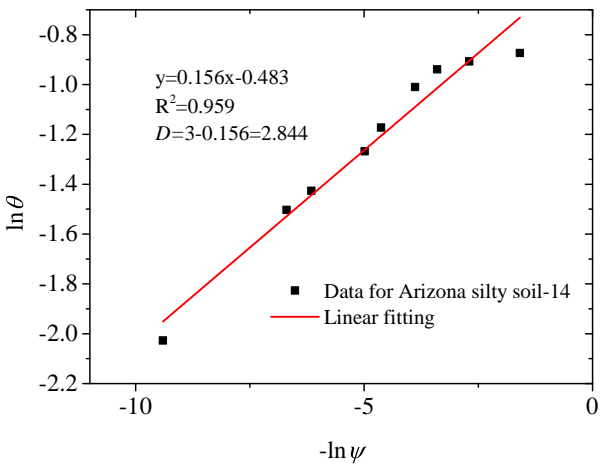

(a)

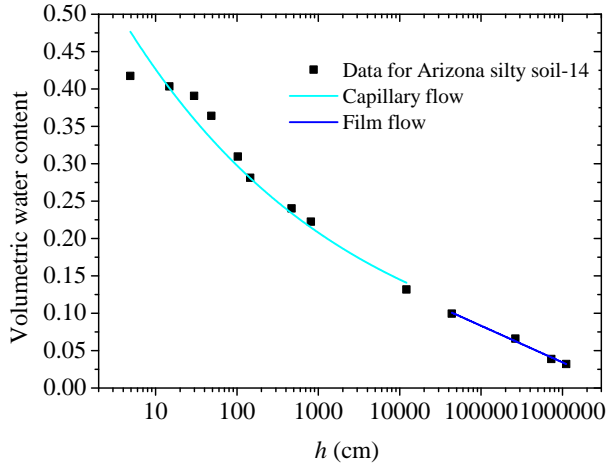

(b)

Fig. 8. (a) Determination of the values of fractal dimension through plotting experimental data of $\ln \theta$ against (-ln $\psi$ ) for Arizona silty soil-14. (b) The model fitting results for Arizona silty soil-14.

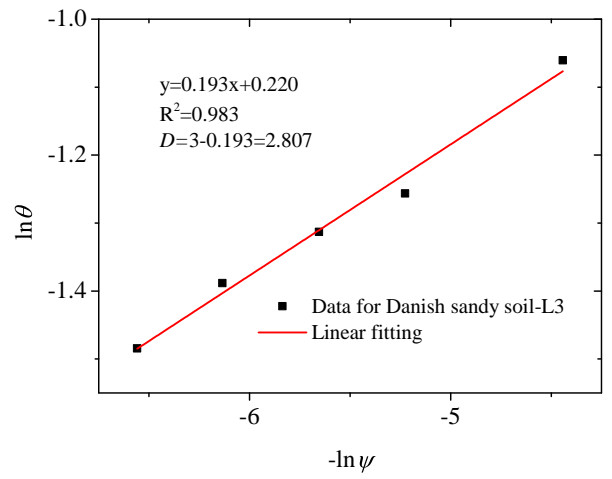

(a)

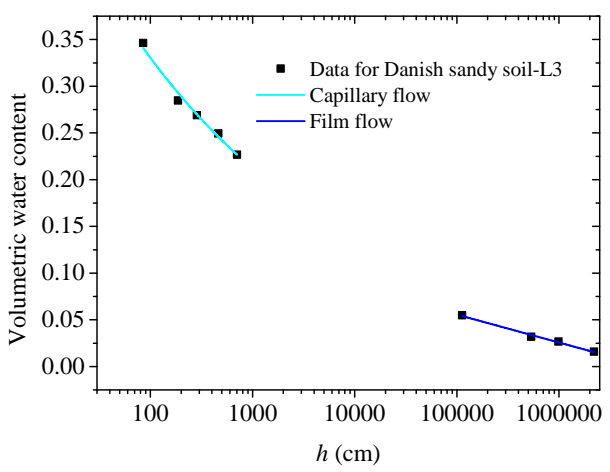

(b)

Fig. 9. (a) Determination of the values of fractal dimension through plotting experimental data of $\ln \theta$ against (-ln $\psi$ ) for Danish sandy soil-L3. (b) The model fitting results for Danish sandy soil-L3.

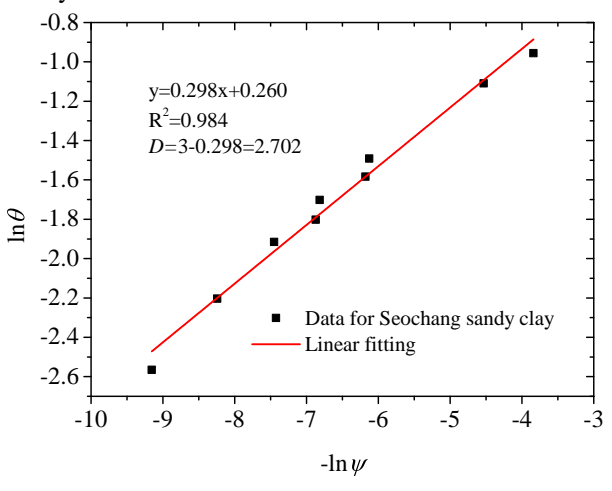

(a)

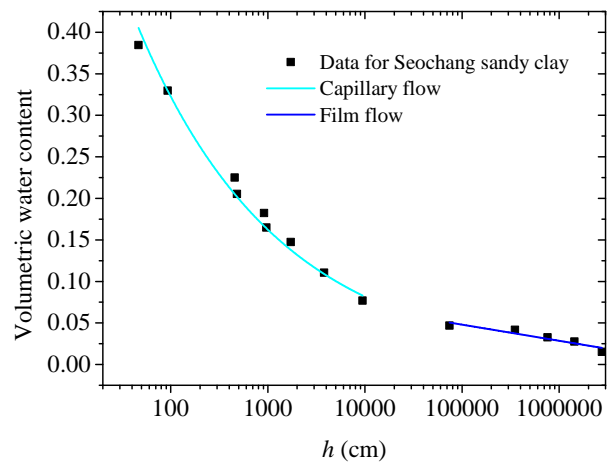

(b)

Fig. 10. (a) Determination of the values of fractal dimension through plotting experimental data of $\ln \theta$ against (-ln $\psi$ ) for Seochang sandy clay. (b) The model fitting results for Seochang sandy clay.

In Table 3, the values of $\psi_{0}$ of various soils are affected by the existence of ingredients in soil and the primary interlayer cations, e.g. $\mathrm{Ca}^{2+}$ and $\mathrm{Na}^{+}$(Montes-H et al., 2003; Schneider and Goss, 2012). Generally, it is recognized that the values of $\psi_{0}$ for various soils are approach to $6.3 \times 10^{6} \mathrm{~cm}$. As demonstrated by Cobos et al. (2014), water content approaches to be zero when matrix suction is in the range of $5 \times 10^{6} \mathrm{~cm}$ and $1.9 \times 10^{7} \mathrm{~cm}$.

After five parameters were determined, the SWCC over complete range of water content can be predicted, as shown in Fig. 1(b) - Fig. 12(b). A validation of the proposed model was conducted using various twelve data sets from the literatures. In Fig. 1(b) - Fig. 12(b), excepting for Fig. 3(b), there are good agreement between the proposed SWCC model over entire range of water content with experimental data. In Fig. 3(b), the relatively poor performance of the proposed model may be the complex structure of Shonai sand. The proposed model over entire range of water content can predict SWCC well at low water content. However, volumetric water content is obviously underestimated when the matric suction $\psi$ ranges from 10 to $30 \mathrm{~cm}$, it is overestimated when the matric suction $\psi$ ranges from 30 to $5,000 \mathrm{~cm}$. 


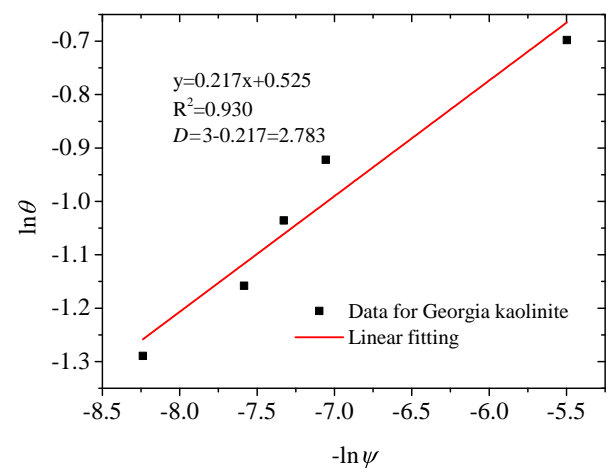

(a)

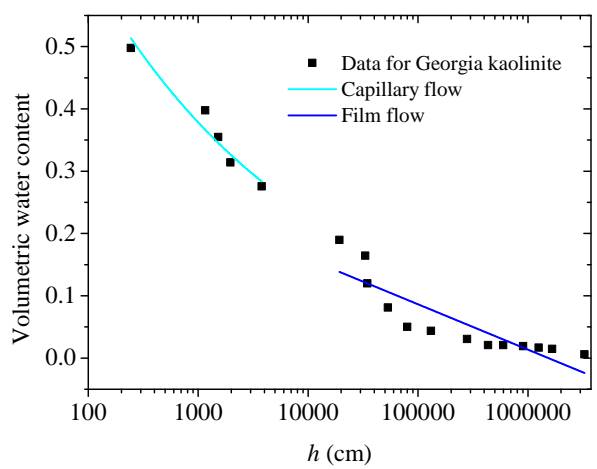

(b)

Fig. 11. (a) Determination of the values of fractal dimension through plotting experimental data of $\ln \theta$ against (-ln $\psi$ ) for Georgia kaolinite. (b) The model fitting results for Georgia kaolinite.

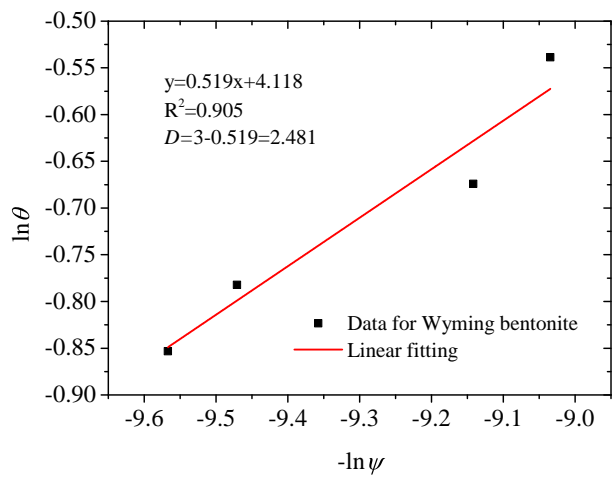

(a)

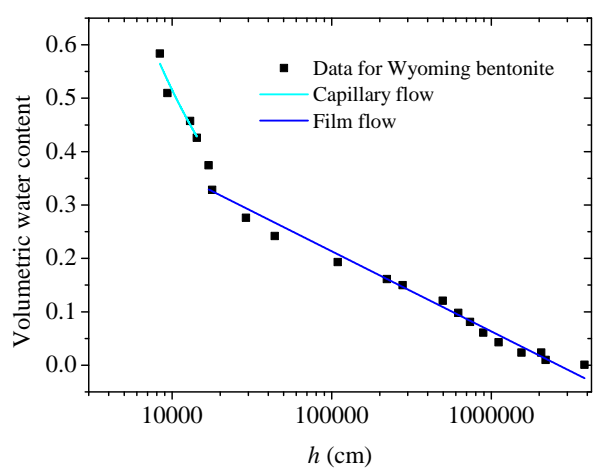

(b)

Fig. 12. (a) Determination of the values of fractal dimension through plotting experimental data of $\ln \theta$ against (-ln $\psi$ ) for Wyoming bentonite. (b) The model fitting results for Wyoming bentonite.

\section{Conclusions}

An alternative fractal SWCC model has been developed with the combination of Tao model and CS model. The proposed model is capable of continuously describing SWCC over the entire range of water content, and it has a simpler form in contrast to other models. The results show that matrix suction and volumetric water content exists a good linear relationship in $\log -\log$ scale, indicating that there is a good performance of fractal geometry in SWCC model of soils. In addition, the determination of the five parameters of the proposed model was elaborated. The application of the presented model was examined by a wide range of experimental data. The results show good agreement between the experimental data and the model.

The SWCC of soils is one of the soils hydraulic properties that are key factors in description of water flow and solute transport in the unsaturated zone. Both hydraulic conductivity function and SWCC are strongly related to soil micro-pore structure. Thus, the future works should be focused on predicting the hydraulic conductivity function based on the proposed SWCC model.

\section{Acknowledgement}

This work is supported from the Hubei Provincial Natural
Science Foundation of China (No. 2018CFA051) and the Fundamental Research Funds for the Central Universities (No. CUGGC04).

\section{Conflict of interest}

The authors declare no competing interest.

Open Access This article is distributed under the terms and conditions of the Creative Commons Attribution (CC BY-NC-ND) license, which permits unrestricted use, distribution, and reproduction in any medium, provided the original work is properly cited.

\section{References}

Al Haj, K.M.A., Standing, J.R. Soil water retention curves representing two tropical clay soils from Sudan. Geotechnique 2016, 66(1): 71-84.

Arya, L.M., Paris, J.F. A physicoempirical model to predict the soil moisture characteristic from particle-size distribution and bulk density data 1. Soil Sci. Soc. Am. J. 1981, 45(6): 1023-1030.

Assouline, S. A model for soil relative hydraulic conductivity based on the water retention characteristic curve. Water Resour. Res. 2001, 37(2): 265-271.

Aubertin, M., Mbonimpa, M., Bussiere, B.R., et al. A model to predict the water retention curve from basic geotechnical properties. Can. Geotech. J. 2003, 40(6): 1104-1122. 
Brooks, R., Corey, A. Hydraulic properties of porous media. Fort Collins, CO, USA, Colorado State University, 1964.

Campbell, G., Shiozawa, S. Prediction of hydraulic properties of soils using particle-size distribution and bulk density data, in Indirect Methods for Estimating the Hydraulic Properties of Unsaturated Soils, edited by T. M. van Genuchten, F. J. Leij and L. J. Lund, University of California, Riverside, Calif, USA, pp. 317-328, 1992.

Chen, C., Hu, K.L., Ren, T.S., et al. A simple method for determining the critical point of the soil water retention curve. Soil Sci. Soc. Am. J. 2017, 81(2): 250-258.

Cobos, D.R., Rivera., L.D., Campbell., G.S. Can the dry-end $(-1$ to $-1000 \mathrm{MPa})$ soil water characteristic curve be well characterized with a single point? Paper Presented at SSSA International Annual Meetings, California, USA, 10-13 November, 2014.

De Bartolo, S., Fallico, C., Severino, G., et al. Two fractal regimes of the soil hydraulic properties. Appl. Math. 2014, 5(12): 1773-1779.

Fredlund, D.G. Unsaturated soil mechanics in engineering practice. J. Geotech. Geoenviron. Eng. 2006, 132(3): 286-321.

Fredlund, D.G., Xing, A.Q. Equations for the soil-water characteristic curve. Can. Geotech. J. 1994, 31(4): 521532.

Fredlund, D.G., Xing, A.Q., Fredlund, M.D., et al. The relationship of the unsaturated soil shear strength to the soil-water characteristic curve. Can. Geotech. J. 1996, 33(3): 440-448.

Gallipoli, D., Gens, A., Sharma, R., et al. An elasto-plastic model for unsaturated soil incorporating the effects of suction and degree of saturation on mechanical behaviour. Géotechnique 2003, 53(1): 123-135.

Iden, S.C., Durner, W. Comment on "Simple consistent models for water retention and hydraulic conductivity in the complete moisture range" by A. Peters. Water Resour. Res. 2014, 50(9): 7530-7534.

Jensen, D.K., Tuller, M., de Jonge, L.W., et al. A new twostage approach to predicting the soil water characteristic from saturation to oven-dryness. J. Hydrol. 2015, 521: 498-507.

Kosugi, K. Lognormal distribution model for unsaturated soil hydraulic properties. Water Resour. Res. 1996, 32(9): 2697-2703.

Kravchenko, A., Zhang, R.D. Estimating the soil water retention from particle-size distributions: A fractal approach. Soil Sci. 1998, 163(3): 171-179.

Lebeau, M., Konrad, J.M. A new capillary and thin film flow model for predicting the hydraulic conductivity of unsaturated porous media. Water Resour. Res. 2010, 46, W12554.

Likos, W.J., Lu, N. Automated humidity system for measuring total suction characteristics of clay. Geotech. Test. J. 2003, 26(2): 179-190.

Lu, N. Generalized soil water retention equation for adsorption and capillarity. J. Geotech. Geoenviron. Eng. 2016, 142(10): 04016051.
Lu, S., Ren, T., Gong, Y., et al. Evaluation of three models that describe soil water retention curves from saturation to oven dryness. Soil Sci. Soc. Am. J. 2008, 72(6): 15421546.

Mandelbrot, B.B. The fractal geometry of nature. New York, USA, WH freeman, 1982.

Mbonimpa, M., Aubertin, M., Maqsoud, A., et al. Predictive model for the water retention curve of deformable clayey soils. J. Geotech. Geoenviron. Eng. 2006, 132(9): 11211132.

Mehta, B.K., Shiozawa, S., Nakano, M. Hydraulic-properties of a sandy soil at low water contents. Soil Sci. 1994, 157(4): 208-214.

Montes-H, G., Duplay, J., Martinez, L., et al. Influence of interlayer cations on the water sorption and swellingshrinkage of MX80 bentonite. Appl. Clay Sci. 2003, 23(5-6): 309-321.

Oh, S., Lu, N., Yun, K.K., et al. Relationship between the soil-water characteristic curve and the suction stress characteristic curve: experimental evidence from residual soils. J. Geotech. Geoenviron. Eng. 2012, 138(1): 47-57.

Pachepsky, Y., Shcherbakov, R.A., Varallyay, G., et al. On obtaining soil hydraulic conductivity curves from water retention curves. Pochvovedenie 1984, 10: 60-72.

Perfect, E. Estimating soil mass fractal dimensions from water retention curves. Geoderma 1999, 88(3-4): 221-231.

Peters, A. Simple consistent models for water retention and hydraulic conductivity in the complete moisture range. Water Resour. Res. 2013, 49: 6765-6780.

Rossi, C., Nimmo, J.R. Modeling of soil-water retention from saturation to oven dryness. Water Resour. Res. 1994, 30(3): 701-708.

Rudiyanto, Sakai, M., van Genuchten, M.T., et al. A complete soil hydraulic model accounting for capillary and adsorptive water retention, capillary and film conductivity, and hysteresis. Water Resour. Res. 2015, 51: 8757-8772.

Russell, A.R. How water retention in fractal soils depends on particle and pore sizes, shapes, volumes and surface areas. Géotechnique 2014, 64(5): 379-390.

Schneider, M., Goss, K.U. Prediction of the water sorption isotherm in air dry soils. Geoderma 2012, 170: 64-69.

Silva, O., Grifoll, J. A soil-water retention function that includes the hyper-dry region through the BET adsorption isotherm. Water Resour. Res. 2007, 43, W11420.

Tao, G., Chen, Y., Kong, L., et al. A simple fractal-based model for soil-water characteristic curves incorporating effects of initial void ratios. Energies 2018, 11(6): 1419.

Tao, H.L., Chen, C., Jiang, P., et al. Soil water characteristic curves based on particle analysis. Procedia Eng. 2017, 174: 1289-1295.

Tokunaga, T.K. Hydraulic properties of adsorbed water films in unsaturated porous media. Water Resour. Res. 2009, 45, W06415.

Tuller, M., Or, D. Water films and scaling of soil characteristic curves at low water contents. Water Resour. Res. 2005, 41, W09403.

Van Genuchten, M.T. A closed-form equation for predicting the hydraulic conductivity of unsaturated soils. Soil Sci. 
Soc. Am. J. 1980, 44: 892-898.

Wang, Y.Q., Jin, M.G., Deng, Z.J. Alternative model for predicting soil hydraulic conductivity over the complete moisture range. Water Resour. Res. 2018, 54: 6860-6876.

Wang, Y.Q., Ma, J.Z., Guan, H.D. A mathematically continuous model for describing the hydraulic properties of unsaturated porous media over the entire range of matric suctions. J. Hydrol. 2016, 541: 873-888.

Wheeler, S.J. Inclusion of specific water volume within an elasto-plastic model for unsaturated soil. Can. Geotech. J. 1996, 33(1): 42-57.
$\mathrm{Xu}$, Y.F. Calculation of unsaturated hydraulic conductivity using a fractal model for the pore-size distribution. Comput. Geotech. 2004, 31(7): 549-557.

Yang, S., Lu, T.H. Study of soil-water characteristic curve using microscopic spherical particle model. Pedosphere 2012, 22(1): 103-111.

Zhang, Z.F. Soil water retention and relative permeability for conditions from oven-dry to full saturation. Vadose Zone J. 2011, 10(4): 1299-1308. 